\title{
Modelling clay materials used in artworks: an infrared spectroscopic investigation
}

\author{
B. H. Stuart ${ }^{1 *}$ (D) P. S. Thomas ${ }^{2}$, M. Barrett ${ }^{3}$ and K. Head ${ }^{3}$
}

\begin{abstract}
Modelling clays are utilised by artists for their malleable properties. One of the challenges in managing collections containing such materials is the variety of commercial compositions available and, therefore, the variation in the requirements for storage and maintenance of such artefacts. The Art Gallery of New South Wales in Australia is responsible for the care of a range of artworks that contain modelling materials, some of which show detrimental property changes and there is concern for the longevity of such works. The aim of the current research is to determine the compositions of the modelling materials utilised in works produced by different artists in the gallery's collection. Infrared spectroscopy was used to identify the main constituents of samples collected from the works of four different artists and a variety of material types were determined. Oil-based, air-hardening and polymer clays of varying composition were identified in the survey of artworks. Signs of deterioration in particular artworks were able to be characterised using spectroscopy, with the mechanisms identified including loss and oxidation of the oil component. Where a polymer clay was chosen by one artist, the distortion of the artwork was due to flow of the material over time and demonstrates the need for an understanding of the long term properties of the materials being used. The study has highlighted the need for conservators to have a detailed understanding of modelling materials to ensure the longevity of artworks containing this class of materials.
\end{abstract}

Keywords: Infrared spectroscopy, Modelling clay, Paraffin, Calcium carbonate, Poly(vinyl chloride), Kaolinite

\section{Introduction}

Modelling clays have long proved popular for use in sculptures due to their malleability and non-drying attributes. There has been a history of the use of natural clays and waxes in sculpture and commercial modelling materials have been in use since the end of the nineteenth century, with materials, such as Plasticine, developed at that time [1-3]. Plasticine was formulated in 1897 in England to produce a non-drying clay suitable for use by sculpture students. Similar products, including Plastilin invented in Germany and Plastilina developed in Italy, were commercially available at the time. A range of commercial compositions have followed, using different components to produce a variety of physical properties. Despite their use over an extended period of time, a

\footnotetext{
*Correspondence: barbara.stuart@uts.edu.au

${ }^{1}$ Centre for Forensic Science, University of Technology Sydney, 15 Broadway, Ultimo, NSW 2007, Australia

Full list of author information is available at the end of the article
}

recognition of the diverse composition types and information reported about the long-term stability of such materials in artworks has been very limited [1].

The first modelling clay formulations appearing in the nineteenth century, such as Plasticine, were oil-based materials. Such materials are a combination of oils, waxes and minerals $[1,2,4]$. A range of oil and wax components have been used, including, for instance, paraffin, beeswax, microcrystalline wax, petroleum jelly, palm oil, castor oil and lanolin. A variety of fillers have been reportedly used in oil-based modelling materials, including gypsum, talc, sulphur, calcite and kaolinite. While the oil-based clays are designed to remain malleable for an extended period of time, other modelling clay types are designed to be malleable during the making of an artwork and then hardened by exposure to air [4]. Air hardening modelling clays provide an alternative to traditional wet ceramic clays that require firing at a high temperature. While wet modelling clays are comprised of clays, silica and fluxes, the main components of air hardening clays are kaolinite 
(or talc) and water combined with minor ingredients such as calcium carbonate, iron oxide, propylene glycol and/or preservatives. Another class of modelling materials designed to be hardened is the polymer clays. These are based on the plasticised polymer poly(vinyl chloride) (PVC) combined with a filler. The formulation emerged from the development of materials in the 1940s designed to replace the phenolic polymer resin Bakelite [5]. The malleable material is shaped and hardened by oven heating at lower temperatures than required for traditional ceramic clays.

The Art Gallery of New South Wales (AGNSW) in Australia holds a range of works comprised of modelling clays. In this study, infrared spectroscopy has been used to characterise the modelling materials used in a variety of artworks. Specimens have been able to be collected from artworks that utilise modelling clays and the use of attenuated total reflectance (ATR) spectroscopy has enabled the components used in the different modelling materials employed by the artists to be identified. Infrared spectroscopy has the particular advantage that the organic and inorganic components of modelling clays can be simultaneously identified and an indication of the relative composition is also provided. Such an approach provides a simple method of obtaining information about such materials without the need to carry out complex sample preparation methods. In order to establish the best approach to the conservation and storage of items produced using modelling materials, an understanding of the nature of the materials employed by the artists is required. Additionally, the use of infrared spectroscopy enables degradation of these materials to be investigated and a prediction about the long term behaviour of these materials can be estimated.

\section{Materials and methods}

\section{Sampling}

A scalpel was used to collect samples, which were stored in sealed polyethylene bags until required for analysis. Four artworks at the Art Gallery of NSW were sampled.

1. Mikala Dwyer (1959-), un from the series iffytown 1999, wood shelf, modelling clay, glass, Perspex, audio tape, fabric, glue, synthetic polymer paint, dimensions variable. 100.2002 (Fig. 1).

This work has been maintained in gallery storage at $50-55 \%$ relative humidity and $23{ }^{\circ} \mathrm{C}$ since acquisition in 2002. Two green (one of dry appearance) and one red modelling clay samples were collected. Newly purchased green and red commercial Plasticine samples (Flair Leisure Products PLC) were also examined for comparison purposes.

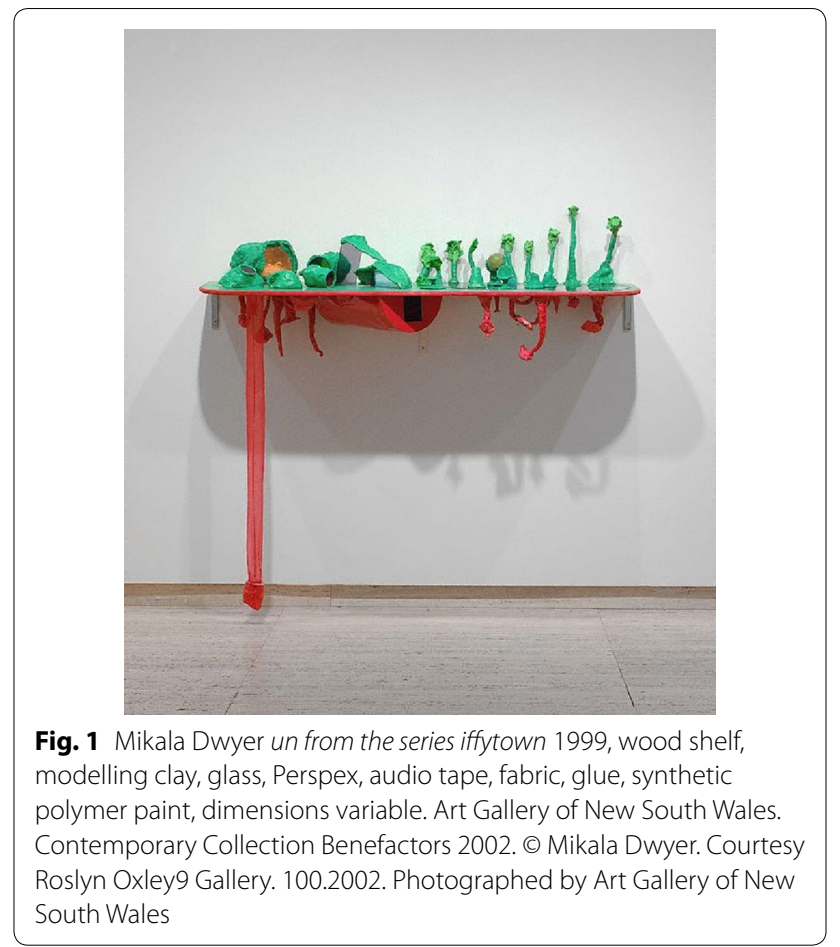

2. Margel Hinder (1906-95), Untitled maquette for sculpture date unknown, soldered metal on modelling clay base, $9 \mathrm{~cm} \times 7 \mathrm{~cm} \times 6 \mathrm{~cm}$ overall. 18.2003.5; Margel Hinder Untitled maquette for sculpture date unknown, soldered metal on modelling clay and wood base, $13 \mathrm{~cm} \times 7 \mathrm{~cm} \times 8 \mathrm{~cm}$ overall. 18.2003.7 (Fig. 2).

Samples were collected from the underside of the bases of the two works.

3. Montien Boonma (1953-2000), Perfumed paintings and stools 1995-1997, paper, wood, herbs, modelling clay, two paintings: each approximately $95 \mathrm{~cm} \times 45 \mathrm{~cm}$, two stools: each approximately $20 \mathrm{~cm} \times 40 \mathrm{~cm} \times 22 \mathrm{~cm} .217 .2002$ (Fig. 3).

Samples were collected from the bases of the two stools of this work.

4. Amanda Marburg (1976-), Giving the devil his dues 2004, oil on canvas, modelling clay on board encased in Perspex covered plinth, stretcher: $101.6 \mathrm{~cm} \times 133.1 \mathrm{~cm} \times 3 \mathrm{~cm}$, plinth: $65 \mathrm{~cm} \times 95 \mathrm{~cm} \times 145 \mathrm{~cm} .321 .2015$ (Fig. 4).

A green sample was collected. There is evidence of movement and collapse of components in this work associated with changes to the properties of the modelling material.

\section{Infrared spectroscopy}

Attenuated total reflectance (ATR) spectra were acquired for each sample at a resolution of $4 \mathrm{~cm}^{-1}$ using a Nicolet 

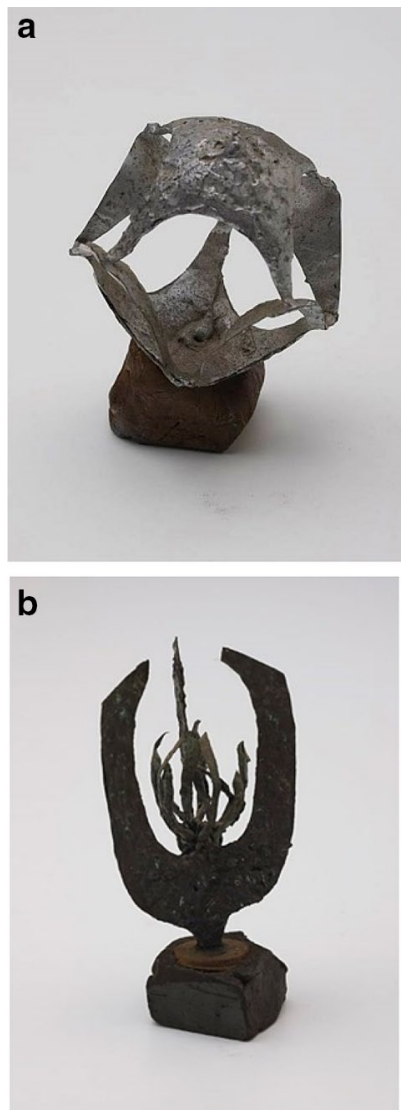

Fig. 2 a Margel Hinder Untitled maquette for sculpture date unknown, soldered metal on modelling clay base, $9 \mathrm{~cm} \times 7 \mathrm{~cm} \times 6 \mathrm{~cm}$ overall. Art Gallery of New South Wales. Gift of Enid Hawkins 2003. @ Estate of Margel Hinder. 18.2003.5. Photographed by Art Gallery of New South Wales. b Margel Hinder Untitled maquette for sculpture date unknown, soldered metal on modelling clay and wood base, $13 \mathrm{~cm} \times 7 \mathrm{~cm} \times 8 \mathrm{~cm}$ overall. Art Gallery of New South Wales. Gift of Enid Hawkins 2003. @ Estate of Margel Hinder. 18.2003.7. Photographed by Art Gallery of New South Wales

iS10 Fourier transform infrared (FTIR) spectrometer equipped with a diamond ATR accessory. 64 scans were collected over the range $4000-500 \mathrm{~cm}^{-1}$. Spectra were recorded in triplicate and representative spectra are presented in this paper.

\section{Scanning electron microscopy-energy dispersive spectroscopy}

Energy dispersive spectroscopy (EDS) was carried out using a Zeiss Supra 55VP scanning electron microscope (SEM) fitted with an Oxford EDS system. Representative samples for each artwork were placed on carbon stubs and sputter coated with $10 \mathrm{~nm}$ gold-palladium coating prior to analysis. EDS spectra were then collected using $15 \mathrm{kV}$ acceleration at a working distance of $8.5 \mathrm{~mm}$ on five regions of a specimen and averaged to determine the indicative elemental content.

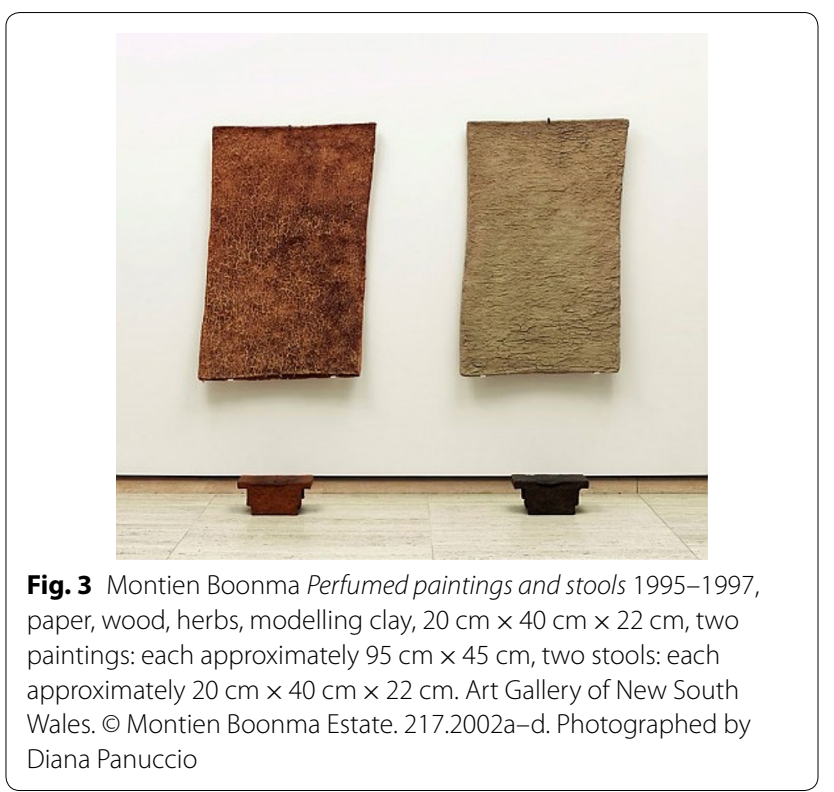

\section{Results and discussion \\ Dwyer artwork}

Infrared spectra of the green coloured samples collected from the Dwyer sculpture, Un, are shown in Fig. 5 and the main band assignments are summarised in Table 1. The spectra show strong bands characteristic of calcium carbonate $\left(\mathrm{CaCO}_{3}\right)$ at 712,872 and $1414 \mathrm{~cm}^{-1}$ and two very weak bands observed at 1790 and $2520 \mathrm{~cm}^{-1}$ also indicate $\mathrm{CaCO}_{3}$ is present [6-9]. SEM-EDS analysis also supports the presence of $\mathrm{CaCO}_{3}$ in this sample (Table 2). The bands in the $\mathrm{C}-\mathrm{H}$ stretching region below $3000 \mathrm{~cm}^{-1}$ indicate an aliphatic hydrocarbon is present. The lack of evidence of aromatic and carbonyl groups indicates that the hydrocarbon constituent is of petrochemical origin, most likely paraffin oil (also known as mineral oil) and/or paraffin wax [10-14]. As the infrared spectrum of paraffin oil and wax are very similar, it is difficult to determine the relative contribution to the overall composition of this modelling clay. The presence of $\mathrm{CaCO}_{3}$ and paraffin components confirms that this modelling material is an oil-based modelling clay, such as Plasticine. Based upon industrial formulations, the pigment used in the green sample is likely to be Pigment Green 7 (phthalocyanine green), but as it is in a low concentration $(<1 \mathrm{w} \%)$ the infrared bands for the pigment are not detectable in the spectrum.

The infrared spectrum of the newly purchased green commercial Plasticine sample is also illustrated in Fig. 5 for comparison. The spectrum shows bands at similar wavenumbers to those observed for the green Dwyer samples, but stronger hydrocarbon bands are visible in the spectrum of the new Plasticine. Additional bands at 


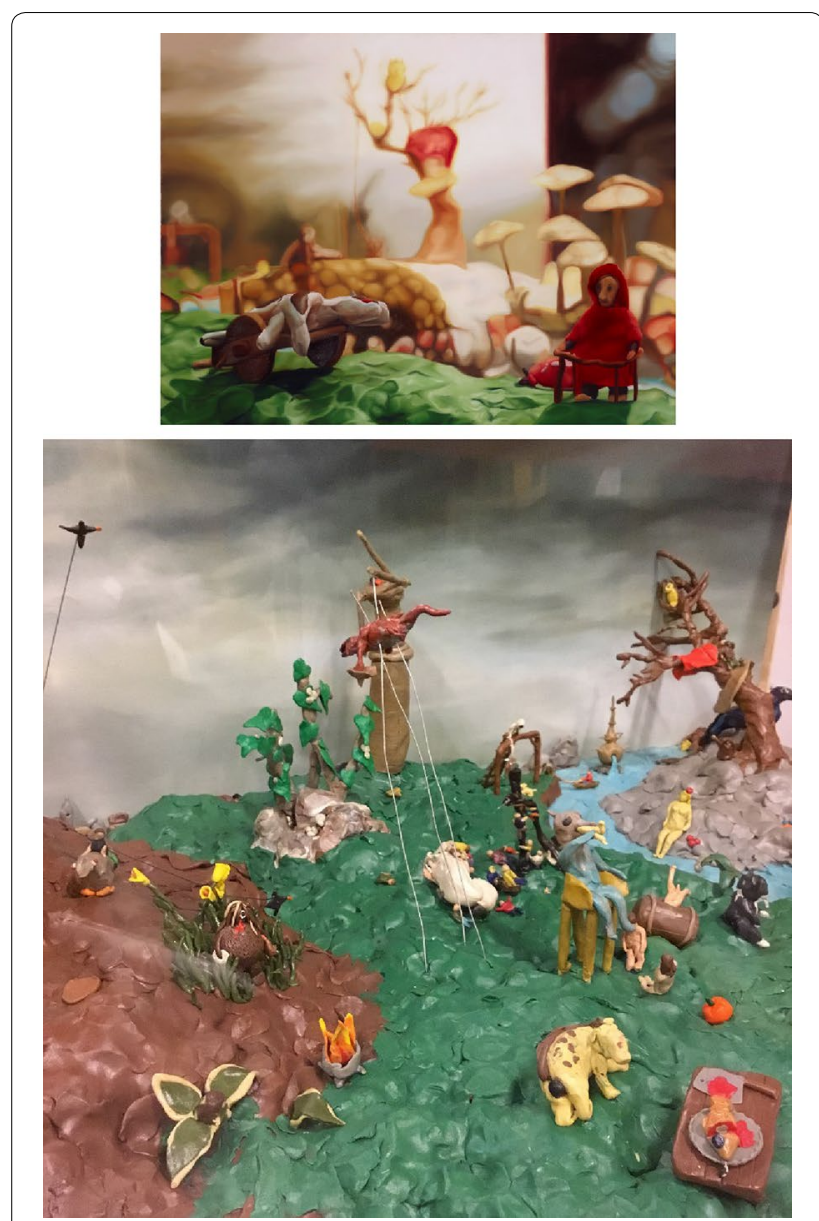

Fig. 4 Amanda Marburg Giving the devil his dues 2004, oil on canvas, modelling clay on board encased in Perspex covered plinth, stretcher: $101.6 \mathrm{~cm} \times 133.1 \mathrm{~cm} \times 3 \mathrm{~cm}$, plinth: $65 \mathrm{~cm} \times 95 \mathrm{~cm} \times 145 \mathrm{~cm}$. Art Gallery of New South Wales. Gift of ARTAND Australia 2015. Donated through the Australian Government's Cultural Gifts Program. (๑ Amanda Marburg. 321.2015. Photographed by Jenni Carter

717,1378 and $1463 \mathrm{~cm}^{-1}$ are observed as shoulders on the overlapping $\mathrm{CaCO}_{3}$ bands in this spectrum. The presence of these bands, along with the sharp aliphatic $\mathrm{C}-\mathrm{H}$ stretching bands, confirm the presence of paraffin $[10,11$, $13,14]$.

The infrared absorbance values associated with the paraffin bands are notably reduced for the Dwyer samples compared to those observed for new Plasticine. The spectrum recorded for the 'dry' green sample collected from the same sculpture shows an even greater reduction in the paraffin band absorbance relative to the $\mathrm{CaCO}_{3}$ bands. Thus, the loss of the paraffin component appears to be the cause of the change in the properties of the green material employed for this sculpture.

The infrared spectra of the red sample collected from the Dwyer sculpture and newly purchased red Plasticine sample are shown in Fig. 6. As for the green samples, the main bands observed may be attributed to paraffin and $\mathrm{CaCO}_{3}$ and confirm that the material used is also an oil-based modelling clay (Table 1). The red pigment used is most likely Pigment Red 170 (naphthol red), but at the concentration used does not show detectable infrared bands. Unlike the green modelling clay used in this artwork, there is no significant reduction in the relative absorbance values for the paraffin bands for the red Dwyer sample. The difference in behaviour of the green and red modelling clays with age may be associated with the positioning of their use in the sculpture. The green modelling clay was used on the upper part of the sculpture, while the red modelling clay was used only on the lower part of the sculpture (Fig. 1). The top of the sculpture is more exposed and may have been subject to greater temperature variation due to lighting, thus leading to a preferential loss of paraffin. Although the use of paraffin in oil-based clays assists in maintaining the nondrying properties due to the relatively low volatility, as paraffins contain a mixture of hydrocarbons and vary in composition, the loss of certain fractions of paraffin is possible particularly when exposed to elevated temperatures over long periods of time [15].

There is, however, an indication of some change to the red modelling clay utilised in this work. The appearance of small bands near 1730 and $1720 \mathrm{~cm}^{-1}$ in the spectrum collected for the red Dwyer sample is likely to be associated with oxidation products of paraffin, such as ketones and esters [16-18]. Initially paraffins oxidise in air to form hydroperoxides that decompose to form oxidation products including ketones, aldehydes and esters. The small bands in the carbonyl region may be attributed to the presence of a small quantity of esters and/or ketones on the surface of the red Dwyer material. Although oils/ waxes can contain ketones and esters, these are not likely in the synthetic oil used in this material. Small bands appearing as shoulders at 1030 and $1190 \mathrm{~cm}^{-1}$ also support the presence of oxidation of the modelling material as the $\mathrm{C}-\mathrm{O}$ and $\mathrm{C}-\mathrm{C}$ stretching bands in this region are associated with the production of such decomposition products [17].

\section{Hinder artwork}

The infrared spectrum of the sample collected from the Hinder sculpture, Untitled maquette for sculpture (18.2003.5), is illustrated in Fig. 7 and the corresponding band assignments are provided in Table 3. The spectrum collected from Untitled maquette for sculpture (18.2003.7) by this artist showed the same bands as that for the 18.2002 .5 piece. The main bands appearing in the spectra are characteristic bands of $\mathrm{CaCO}_{3}$ and oil/wax, confirming that an oil-based modelling clay was also used 


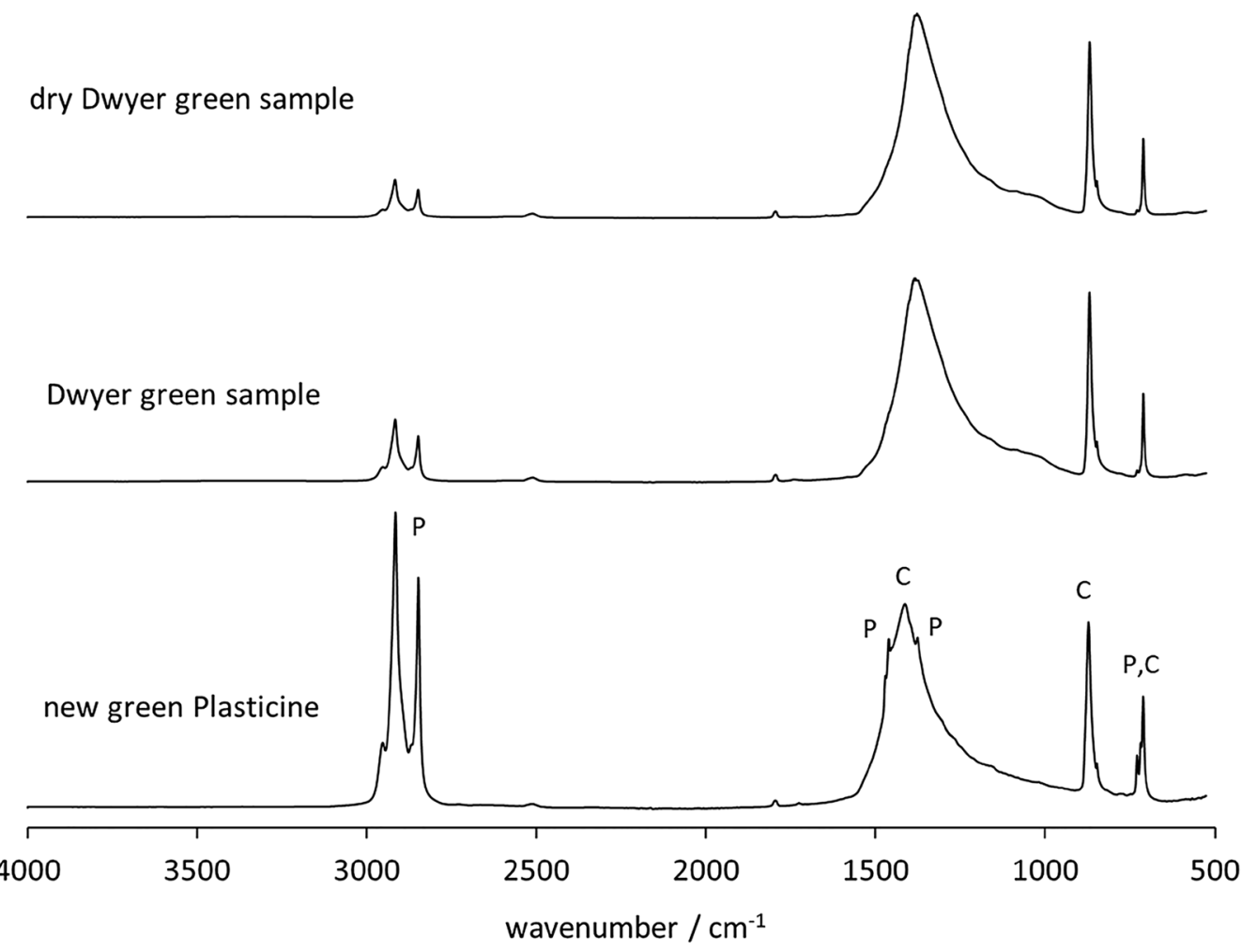

Fig. 5 Infrared spectra of green samples collected from Dwyer artwork. P paraffin, C calcium carbonate

Table 1 Major infrared band assignments for modelling clay samples from Dwyer artworks

\begin{tabular}{|c|c|c|}
\hline Wavenumber $/ \mathrm{cm}^{-1}$ & Band assignments & References \\
\hline 712 & $\mathrm{CaCO}_{3} \mathrm{C}-\mathrm{O}$ bending & {$[6-9]$} \\
\hline 717,728 & Paraffin $\mathrm{C}-\mathrm{H}$ rocking & {$[10,11,13,14]$} \\
\hline 849,872 & $\mathrm{CaCO}_{3} \mathrm{C}-\mathrm{O}$ bending & {$[6-9]$} \\
\hline 1030 & $\begin{array}{l}\text { Oxidation products } \mathrm{C}-\mathrm{O} \text { stretch- } \\
\text { ing }\end{array}$ & {$[17,23]$} \\
\hline 1190 & $\begin{array}{l}\text { Oxidation products } \mathrm{C}-\mathrm{C} \text { stretch- } \\
\text { ing }\end{array}$ & {$[17,23]$} \\
\hline 1367,1378 & Paraffin $\mathrm{C}-\mathrm{H}$ bending & {$[10,11,13,14]$} \\
\hline 1414 & $\mathrm{CaCO}_{3} \mathrm{C}-\mathrm{O}$ stretching & {$[6-9]$} \\
\hline 1463,1470 & Paraffin $\mathrm{C}-\mathrm{H}$ bending & {$[10,11,13,14]$} \\
\hline 1720,1730 & $\begin{array}{l}\text { Oxidation products } \mathrm{C}=\mathrm{O} \\
\text { stretching }\end{array}$ & {$[16-18]$} \\
\hline 1790 & $\mathrm{CaCO}_{3} \mathrm{C}=\mathrm{O}$ stretching & {$[6-9]$} \\
\hline 2520 & $\begin{array}{l}\mathrm{CaCO}_{3} \text { overtone/combination } \\
\text { band }\end{array}$ & {$[7,8]$} \\
\hline $2847,2874,2916,2950$ & Paraffin $\mathrm{C}-\mathrm{H}$ stretching & {$[10,11,13,14]$} \\
\hline
\end{tabular}

in these works. Aliphatic long chain hydrocarbons, most likely paraffin, are indicated by the strong sharp $\mathrm{C}-\mathrm{H}$ stretching bands in the $3000-2800 \mathrm{~cm}^{-1}$ region. Smaller bands in the spectrum shown in Fig. 7 also provide
Table 2 EDS analysis of representative model clay samples

\begin{tabular}{ll}
\hline Sample & Main element composition (w\%) \\
\hline Dwyer green & $\mathrm{O}(59.0), \mathrm{Ca}(30.6), \mathrm{Si}(0.5)$ \\
Hinder & $\mathrm{O}(50.1), \mathrm{Ca}(15.6), \mathrm{S}(8.9), \mathrm{Si}(4.8), \mathrm{Fe}(2.1), \mathrm{Al}(1.9), \mathrm{Cl}(1.6)$ \\
Boonma & $\mathrm{O}(47.7), \mathrm{Si}(20.5), \mathrm{Ca}(11.2), \mathrm{Al}(5.7), \mathrm{K}(4.4), \mathrm{Mg}(0.7)$ \\
Marburg & $\mathrm{O}(46.1), \mathrm{Ca}(15.8), \mathrm{Ti}(11.6), \mathrm{Si}(10.2), \mathrm{Al}(4.9), \mathrm{Mg}(1.2)$, \\
& $\mathrm{K}(0.8), \mathrm{Na}(0.8), \mathrm{Cl}(0.7)$
\end{tabular}

evidence that the hydrocarbon components have undergone change; the relative intensities of the paraffin and calcium carbonate bands indicate a notable reduction in the oil component compared to new Plasticine (as illustrated in Fig. 5).

The appearance of small bands below $800 \mathrm{~cm}^{-1}$ in the spectrum shown in Fig. 7 provides evidence of low concentrations of the minerals, gypsum $\left(\mathrm{CaSO}_{4} \cdot 2 \mathrm{H}_{2} \mathrm{O}\right)$ and goethite $(\mathrm{FeOOH})$ in the Hinder modelling clay. Bands at 603 and $675 \mathrm{~cm}^{-1}$ and at 3553 and $3406 \mathrm{~cm}^{-1}$ superimposed upon the broad $\mathrm{O}-\mathrm{H}$ stretching band are characteristic of gypsum $[19,20]$. A small band at $766 \mathrm{~cm}^{-1}$ and a contribution to the broad $\mathrm{O}-\mathrm{H}$ stretching region indicates goethite is present [21, 22]. SEM-EDS analysis of the Hinder sample indicates the presence of goethite, 


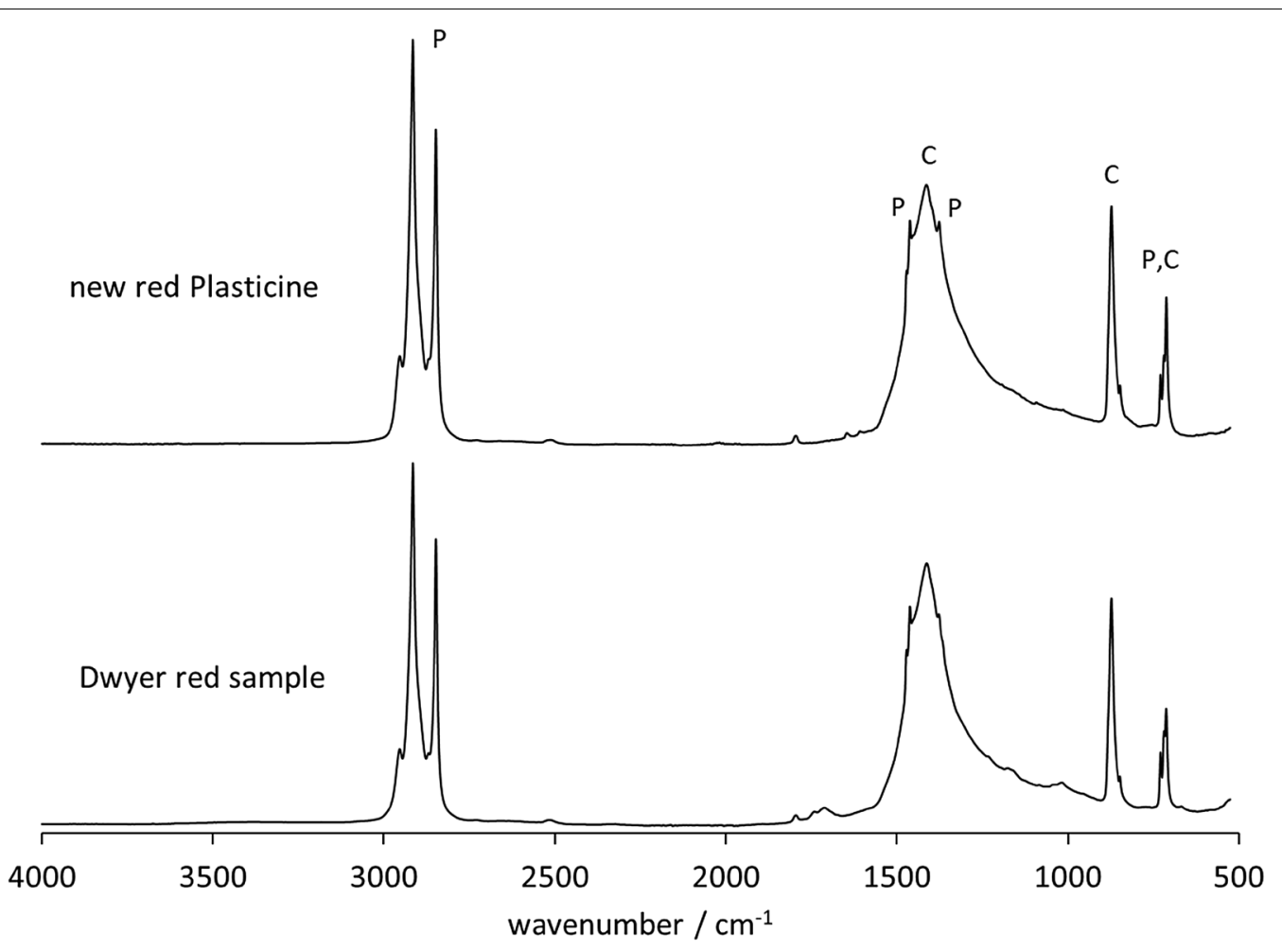

Fig. 6 Infrared spectra of red samples from Dwyer artwork. P paraffin, C calcium carbonate

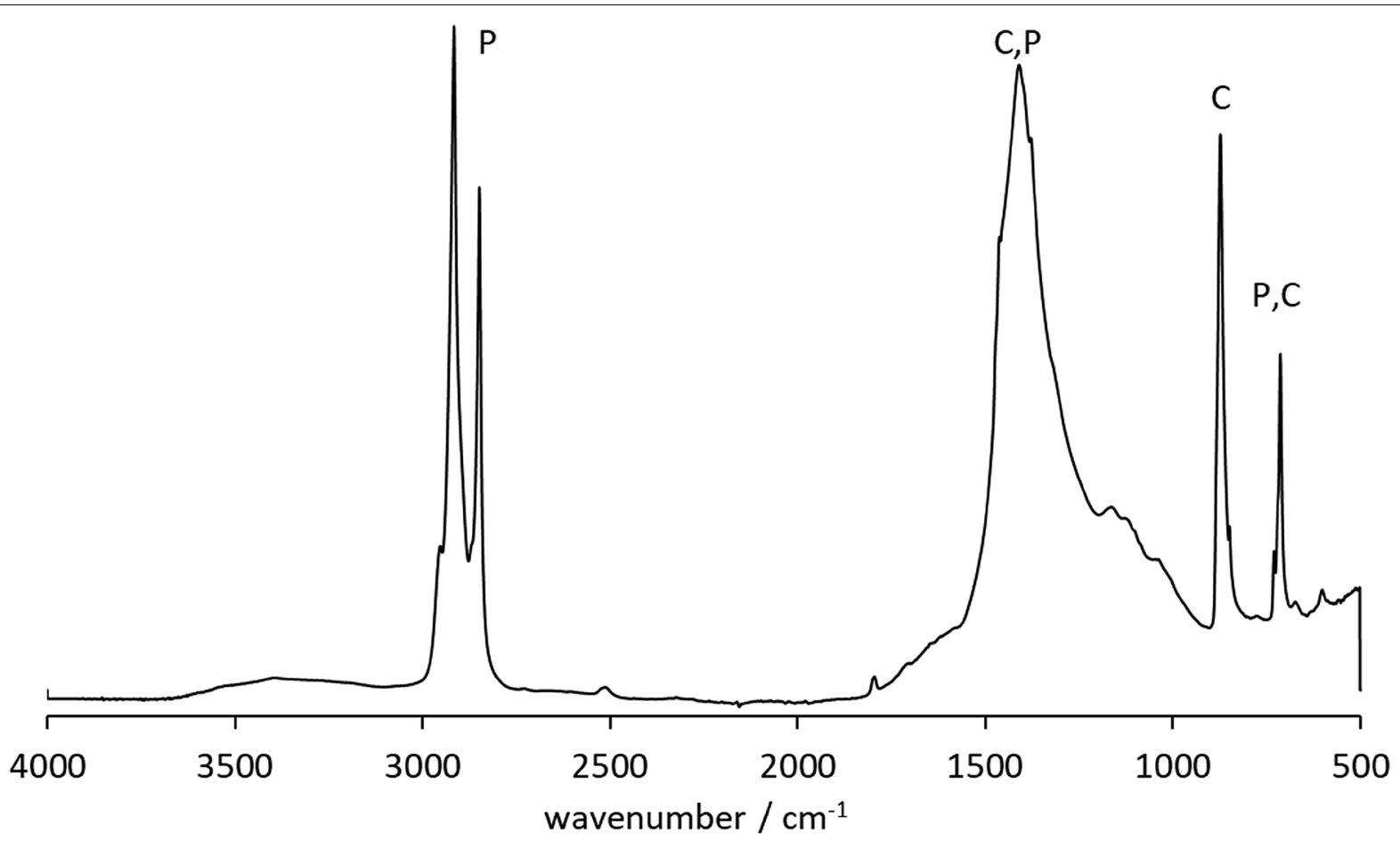

Fig. 7 Infrared spectrum of sample from Hinder artwork. P paraffin, C calcium carbonate 
Table 3 Major infrared band assignments for modelling clay samples from Hinder artworks

\begin{tabular}{|c|c|c|}
\hline Wavenumber $/ \mathrm{cm}^{-1}$ & Band assignments & References \\
\hline 595 & Gypsum S-O bending & {$[19,20]$} \\
\hline 664 & Gypsum S-O stretching & {$[19,20]$} \\
\hline 711 & $\mathrm{CaCO}_{3} \mathrm{C}-\mathrm{O}$ bending & {$[6-9]$} \\
\hline 728 & Paraffin $\mathrm{C}-\mathrm{H}$ rocking & {$[10,11,13,14]$} \\
\hline 766 & Goethite $\mathrm{O}-\mathrm{H}$ bending & {$[21,22]$} \\
\hline 852,872 & $\mathrm{CaCO}_{3} \mathrm{C}-\mathrm{O}$ bending & {$[6-9]$} \\
\hline \multirow[t]{2}{*}{$1000-1300$} & Oxidation products $\mathrm{C}-\mathrm{O}$ and $\mathrm{C}-\mathrm{C}$ stretching & {$[17,23]$} \\
\hline & Gypsum S-O stretching & {$[19,20]$} \\
\hline 1385 & Paraffin $\mathrm{C}-\mathrm{H}$ bending & {$[10,11,13,14]$} \\
\hline 1413 & $\mathrm{CaCO}_{3} \mathrm{C}-\mathrm{O}$ stretching & {$[6-9]$} \\
\hline 1456 & Paraffin $\mathrm{C}-\mathrm{H}$ bending & {$[10,11,13,14]$} \\
\hline \multirow[t]{3}{*}{$1550-1750$} & Water $\mathrm{O}-\mathrm{H}$ bending & {$[23]$} \\
\hline & Gypsum $\mathrm{O}-\mathrm{H}$ bending & {$[19,20]$} \\
\hline & Oxidation products $\mathrm{C}=\mathrm{O}$ stretching & {$[16-18,23]$} \\
\hline 1790 & $\mathrm{CaCO}_{3} \mathrm{C}=\mathrm{O}$ stretching & {$[6-9]$} \\
\hline 2522 & $\mathrm{CaCO}_{3}$ overtone/combination band & {$[7,8]$} \\
\hline 2725 & Aldehyde $\mathrm{O}=\mathrm{C}-\mathrm{H}$ stretching & {$[23]$} \\
\hline $2848,2865,2917,2948$ & Paraffin C-H stretching & {$[10,11,13,14]$} \\
\hline \multirow[t]{4}{*}{$3100-3700$} & Water $\mathrm{O}-\mathrm{H}$ stretching & {$[17,23]$} \\
\hline & Oxidation products $\mathrm{O}-\mathrm{H}$ stretching & {$[23]$} \\
\hline & Gypsum O-H stretching & {$[19,20]$} \\
\hline & Goethite $\mathrm{O}-\mathrm{H}$ stretching & {$[21,22]$} \\
\hline
\end{tabular}

with the presence of a small quantity of Fe detected (Table 2). The detection of sulphur also supports the presence of gypsum. The presence of goethite, along with calcite $\left(\mathrm{CaCO}_{3}\right)$, indicates that a brown ochre was used to produce the colour of the modelling clay. It is noted that the quantity of $\mathrm{S}$ is relatively high $(8.9 \mathrm{w} \%)$ and suggests that elemental sulphur is also present. Some modelling clay brands, particularly earlier compositions, are known to contain elemental sulphur [2].

The carbonyl region between 1800 and $1600 \mathrm{~cm}^{-1}$ in Fig. 7 is broad and comprised of a mixture of contributions from different classes of $\mathrm{C}=\mathrm{O}$ containing compounds, such as ketones and aldehydes, contributing to this region $[17,23]$. The presence of a small diagnostic aldehyde band at $2725 \mathrm{~cm}^{-1}$ supports the presence of this class of compound [23]. The appearance of a broad $\mathrm{O}-\mathrm{H}$ stretching band in the $3700-3100 \mathrm{~cm}^{-1}$ region, as well as a shoulder appearing at $1135 \mathrm{~cm}^{-1}$, are indicative of alcohols. Some water is likely to also be contributing to the $\mathrm{O}-\mathrm{H}$ stretching band. As previously stated, alcohols, ketones and aldehydes can result from the oxidation of oils [16-18]. Although these types of compounds are known to be present in natural oils and waxes, the lack of spectral bands due to fatty acid esters, free fatty acids and aromatic compounds supports the idea that synthetic rather than natural oil/wax has been used in the modelling clay employed in this work [24, 25]. Thus, some oxidation of the oil/wax used in for this work is likely to have occurred and is detected on the surface of this work.

\section{Boonma artwork}

Figure 8 illustrates the infrared spectrum for the sample collected from the lighter coloured stool contained in the Boonma artwork, Perfumed paintings and stools. The spectrum for the sample collected from the darker coloured stool from the same work shows identical bands to those observed in Fig. 8. The infrared band assignments are listed in Table 4. A comparison with the previously described spectra demonstrates a difference in the composition of the modelling material used for the Boonma work. Rather than the strong $\mathrm{CaCO}_{3}$ bands that were observed for the spectra of the previous modelling clays, the major inorganic component of this material is identified as the clay mineral kaolinite. Kaolinite is a layered silicate mineral with the composition $\mathrm{Al}_{2} \mathrm{Si}_{2} \mathrm{O}_{5}(\mathrm{OH})_{4}$. This clay mineral is readily identified due to the appearance of the unique pattern in the $3700-3600 \mathrm{~cm}^{-1}$ region due to $\mathrm{O}-\mathrm{H}$ stretching and also shows $\mathrm{Si}-\mathrm{O}$ stretching and $\mathrm{O}-\mathrm{H}$ bending bands in the region below $1200 \mathrm{~cm}^{-1}[21,26]$. Bands due to $\mathrm{CaCO}_{3}$ are still observed in the Boonma spectrum, but the relative intensities of these are much 


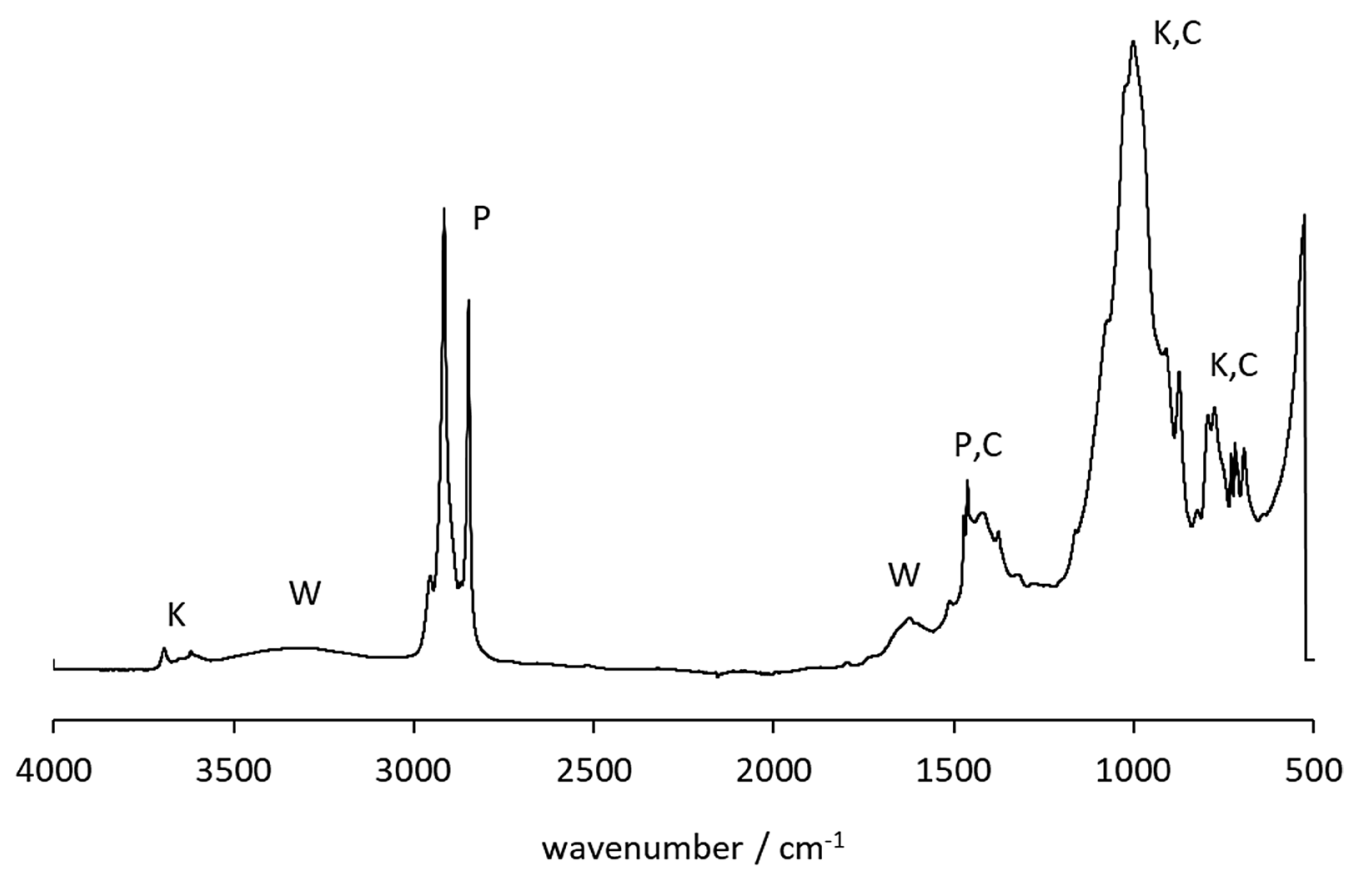

Fig. 8 Infrared spectrum of sample from Boonma artwork. $K$ kaolinite, $W$ water, $P$ paraffin, $C$ calcium carbonate

Table 4 Major infrared band assignments for modelling clay samples from Boonma artwork

\begin{tabular}{|c|c|c|}
\hline Wavenumber $/ \mathrm{cm}^{-1}$ & Band assignments & References \\
\hline 712 & $\mathrm{CaCO}_{3} \mathrm{C}-\mathrm{O}$ bending & {$[6-9]$} \\
\hline 718,729 & Paraffin $\mathrm{C}-\mathrm{H}$ rocking & {$[10,11,13,14]$} \\
\hline 849,876 & $\mathrm{CaCO}_{3} \mathrm{C}-\mathrm{O}$ bending & {$[6-9]$} \\
\hline $700-950$ & Kaolinite $\mathrm{O}-\mathrm{H}$ bending, $\mathrm{Si}-\mathrm{O}$ stretching & {$[21,26]$} \\
\hline $800-1200$ & Kaolinite Si-O stretching & {$[21,26]$} \\
\hline $1000-1300$ & Oxidation products $\mathrm{C}-\mathrm{O}$ and $\mathrm{C}-\mathrm{C}$ stretching & {$[17,23]$} \\
\hline 1378 & Paraffin $\mathrm{C}-\mathrm{H}$ bending & {$[10,11,13,14]$} \\
\hline 1420 & $\mathrm{CaCO}_{3} \mathrm{C}-\mathrm{O}$ stretching & {$[6-9]$} \\
\hline 1461,1472 & Paraffin $\mathrm{C}-\mathrm{H}$ bending & {$[10,11,13,14]$} \\
\hline \multirow[t]{2}{*}{$1600-1700$} & Water $\mathrm{O}-\mathrm{H}$ bending & [23] \\
\hline & Oxidation products $\mathrm{C}=\mathrm{O}$ stretching & {$[16-18,23]$} \\
\hline 1785 & $\mathrm{CaCO}_{3} \mathrm{C}=\mathrm{O}$ stretching & {$[6-9]$} \\
\hline 2525 & $\mathrm{CaCO}_{3}$ overtone/combination band & {$[7,8]$} \\
\hline $2848,2880,2915,2951$ & Paraffin $\mathrm{C}-\mathrm{H}$ stretching & {$[10,11,13,14]$} \\
\hline \multirow[t]{2}{*}{$3100-3600$} & Water $\mathrm{O}-\mathrm{H}$ stretching & [23] \\
\hline & oxidation products $\mathrm{O}-\mathrm{H}$ stretching & {$[23]$} \\
\hline $3624,3638,3688$ & Kaolinite O-H stretching & {$[21,26]$} \\
\hline
\end{tabular}

less than those observed for the compositions used in the previous modelling clays, where $\mathrm{CaCO}_{3}$ was a major constituent. The identification of kaolinite and $\mathrm{CaCO}_{3}$ in this material is supported by SEM-EDS analysis, with more Si than Ca detected for this sample (Table 2).

The spectrum of the Boonma sample also provides evidence of the use of paraffin oil, including sharp aliphatic
$\mathrm{C}-\mathrm{H}$ stretching bands in the $3000-2800 \mathrm{~cm}^{-1}$ region $[10$, $11,13,14]$. However, the relative intensities of the paraffin bands compared to the mineral components are lower than those observed in the earlier oil-based modelling clay spectra. Given that kaolinite is the main component of this modelling material with a smaller quantity of $\mathrm{CaCO}_{3}$, it is probable that an air hardening clay was 


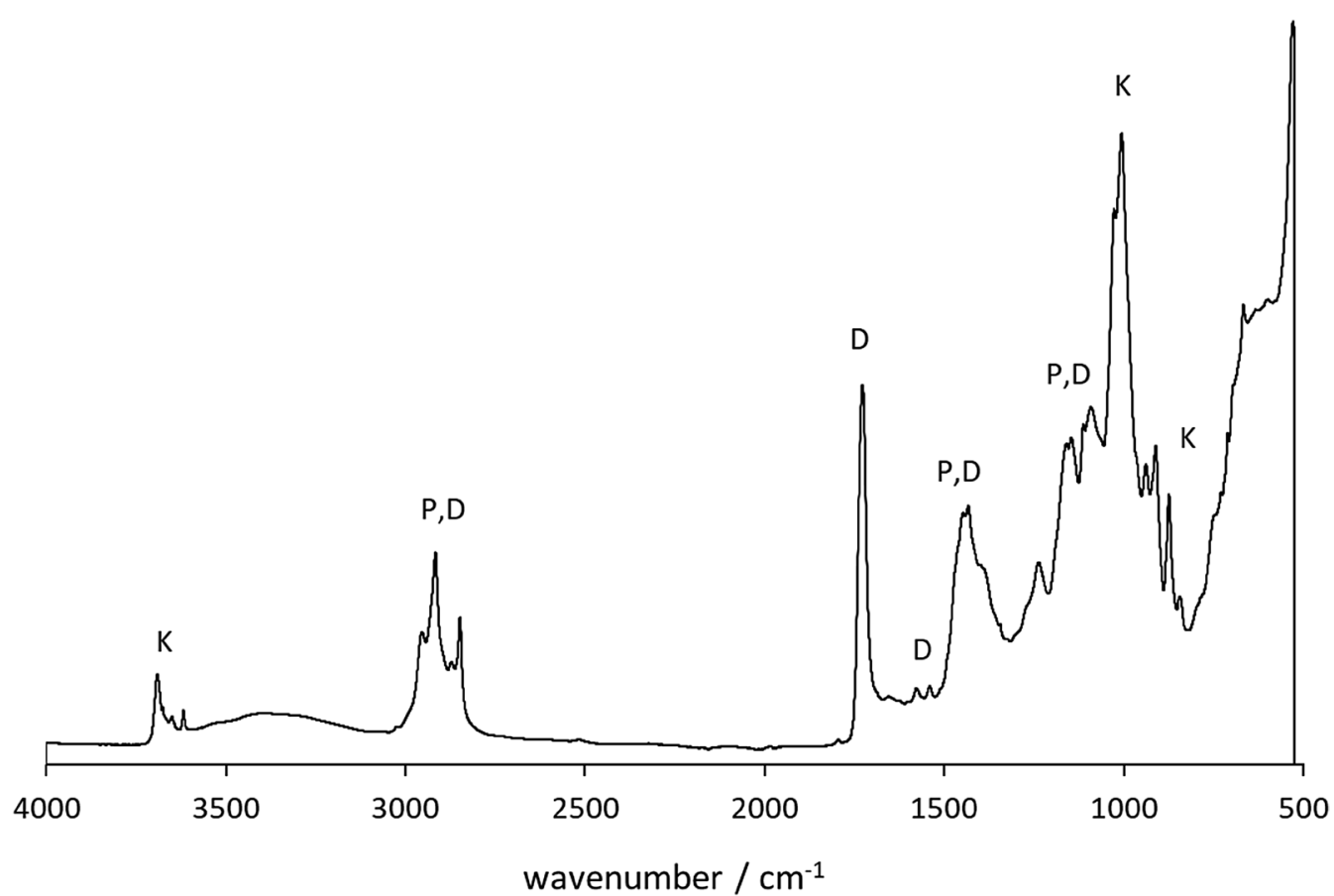

Fig. 9 Infrared spectrum of sample from Marburg artwork. K kaolinite, $P$ poly(vinyl chloride), D DEHP plasticiser

employed by the artist. The presence of an oil may be due to the use of a lubricant in production to reduce friction and adhesion, or by the artist to avoid adhesion to a base (the sample was collected from the base of the stool).

Although adsorbed water has been identified due to the presence of a band near $1634 \mathrm{~cm}^{-1}$, the band in this region is broad and shows a greater absorbance value than would be expected when compared to the broad water $\mathrm{O}-\mathrm{H}$ stretching band centred near $3300 \mathrm{~cm}^{-1}$. This indicates that modes other than water are contributing to the band in this region. The additional bands may be due to oxidation products of the oil. As was observed for the previously discussed works, the $\mathrm{C}=\mathrm{O}$ stretching bands of ketones, aldehydes and alcohols produced by the oxidation of long chain hydrocarbons are likely to be contributing to the broad band in this region. A small carbonyl band at $1721 \mathrm{~cm}^{-1}$ is also observed. Air hardening clays often contain a small quantity of the additive 1,3-bis(hydroxymethyl)-5,5-dimethylhydantoin, used as a preservative, in small quantities $(<1 \mathrm{w} \%)$ and this compound would show a small $\mathrm{C}=\mathrm{O}$ stretching band at in the $1800-1700 \mathrm{~cm}^{-1}$ region, so could also be a contributing factor to the appearance of a carbonyl band in this region.

\section{Marburg artwork}

The infrared spectrum obtained for the Marburg Giving the Devil his dues sample is shown in Fig. 9, with band assignments listed in Table 5 . The spectrum shows bands characteristic of a plasticised poly(vinyl chloride) (PVC) [27-29]. Although there is overlap of the PVC, plasticiser and kaolinite contributions in the spectrum below $1500 \mathrm{~cm}^{-1}$, there are certain characteristic bands in the spectrum. Phthalate esters are commonly employed as plasticisers for PVC in a range of applications and the

Table 5 Major infrared band assignments for modelling clay samples from Marburg artwork

\begin{tabular}{lll}
\hline Wavenumber/cm & Band assignments & References \\
\hline $600-700$ & PVC C-Cl stretching & {$[27-29]$} \\
$700-950$ & Kaolinite O-H bending, Si-O & {$[21,26]$} \\
& stretching & \\
$800-1200$ & Kaolinite Si-O stretching & {$[21,26]$} \\
$1100-1300$ & Plasticiser C-O stretching & {$[27-29]$} \\
$1200-1500$ & PVC C-H bending & {$[27-29]$} \\
& Plasticiser C-H bending & {$[27-29]$} \\
1535,1569 & Plasticiser phthalate ring stretch- & {$[27-29]$} \\
& ing & \\
$1600-1700$ & Water O-H bending & {$[23]$} \\
1725 & Plasticiser C=O stretching & {$[27-29]$} \\
$2800-3000$ & PVC C-H stretching & {$[27-29]$} \\
& Plasticiser C-H stretching & {$[27-29]$} \\
3009 & Plasticiser aromatic C-H stretching & {$[23]$} \\
$3100-3600$ & Water O-H stretching & {$[23]$} \\
$3621,3645,3673,3694$ & Kaolinite O-H stretching & {$[21,26]$} \\
\hline
\end{tabular}


spectrum in Fig. 9 shows evidence that a phthalate plasticiser has been used in the formulation of this modelling clay. The appearance of a strong carbonyl band at $1725 \mathrm{~cm}^{-1}$ combined with a characteristic pair of bands at 1569 and $1535 \mathrm{~cm}^{-1}$ supports the identification of the plasticiser used as diethyl hexyl phthalate (DEHP) [27-29]. Infrared bands due to the clay kaolinite are also observed in the spectrum, particularly the distinctive $\mathrm{O}-\mathrm{H}$ stretching pattern in the $3700-3600 \mathrm{~cm}^{-1}$ region $[21,26]$. The SEM-EDS results provide supporting evidence of the presence of kaolinite (Table 2). The concentrations of $\mathrm{Ca}$ and $\mathrm{Ti}$ also indicate the likely presence of $\mathrm{CaCO}_{3}$ and $\mathrm{TiO}_{2}$, common fillers in this class of materials. Given the overlap of the bands due to these inorganic compounds in the fingerprint region of the infrared spectrum, it is not straightforward to use the infrared bands of these compounds to identify these components. There are no detectable contributions from a pigment in the spectrum. As was observed for the Dwyer samples, the pigment used is likely to have been in a low concentration and/or would overlap with the stronger contributions from the bulk components.

The combination of plasticised PVC and a clay mineral in the formulation demonstrates that the artist has employed a polymer clay to produce this artwork. However, polymer clays require heating to maintain a final shape and produce a hardened material. As the modelling material remains soft, it appears that the artist has not heated the polymer clay material used in this work. Plasticised PVC often suffers excessive creep-the deformation over time when a force is continuously applied [30]. Assuming that the same type of modelling clay has been used throughout the piece, the sections showing movement and collapse are likely to be due to the on-going forces applied by superimposed or inserted components on the plasticised PVC.

\section{Conclusions}

Infrared spectroscopy has enabled modelling materials used in the works by different artists in the AGNSW collection to be characterised. This spectroscopic investigation has demonstrated the use of a variety of source materials by artists, with oil-based, air-hardening and polymer clays being employed in different works. The main components of the modelling materials are able to be readily identified using this approach. Although the pigments are generally not easily detected due to the low concentrations and/or their infrared bands appear in the far-infrared region, it is the principal components, such as clays, oils, waxes, polymers and plasticisers, that influence the physical properties.
Changes associated with degradation of the modelling materials were also determined in this study. For the Dwyer work, a loss of the oil component was identified for one of the modelling clay components of the work. Some oxidation of the oil component of this piece was also noted. The older Hinder material, made of an oil-based modelling clay of similar composition to that of the Dwyer materials, also showed a loss of paraffin but more significant oxidation of the surface was evident. Although the Boonma work utilised an airhardening clay, either the formulation contained oil or the artist used oil as a lubricant, and oxidation of the oil is also evident on the surface of this material. As a consequence, the susceptibility to oil loss and oxidation of the oil-based clays can now be minimised through limiting heat and light sources where possible.

A polymer clay was used for the Marburg work and the use of this material without the required oven heating explains the distortion and collapse of sections of the work over a period of time. The use of a polymer clay demonstrates the need for an understanding of the exact nature of modelling materials in order to ensure long term stability. The plastic deformation and vulnerability to movement of the unfired PVC confirms that specific transport, storage and handling of this work will be required.

It has been demonstrated that an infrared spectroscopic examination of modelling clays used in artworks can provide a relatively straightforward means of characterising the principal components of these materials. This approach also provides insight into the degradation processes and the changes that occur to the modelling clays over time. There is potential to use this as a screening method with subsequent experiments, including chromatography and elemental analysis, providing more detail about the identified compounds.

\section{Abbreviations}

AGNSW: Art Gallery of New South Wales; ATR: attenuated total reflectance; DEHP: diethyl hexyl phthalate; EDS: energy dispersive spectroscopy; FTIR: Fourier transform infrared; PMMA: poly(methyl methacrylate); PVC: poly(vinyl chloride); SEM: scanning electron microscopy; VOC: volatile organic compound.

\section{Authors' contributions}

All authors contributed to the research activities and the preparation of the manuscript. MB collected samples. BS carried out the infrared spectroscopy experiments and analysis. PT and BS carried out SEM-EDS analyses. All authors read and approved the final manuscript.

\section{Funding}

This research was funded partially by the Australian Government through the Australian Research Council.

Availability of data and materials

The data used during the current study are available from the corresponding author on reasonable request. 


\section{Competing interests}

The authors declare that they have no competing interests.

\section{Author details}

${ }^{1}$ Centre for Forensic Science, University of Technology Sydney, 15 Broadway, Ultimo, NSW 2007, Australia. ${ }^{2}$ School of Mathematical and Physical Sciences, University of Technology Sydney, 15 Broadway, Ultimo, NSW 2007, Australia. ${ }^{3}$ Conservation Department, Art Gallery of New South Wales, Art Gallery Rd, Sydney, NSW 2000, Australia.

Received: 4 June 2019 Accepted: 20 October 2019

Published online: 28 October 2019

\section{References}

1. Langlois J, Mary G, Bluzat H, Cascio A, Balcar N, Vandenberghe Y, Cotte M. Analysis and conservation of modern modelling materials found in August Rodin's sculptures. Stud Conserv. 2017;62:247-65.

2. Eggert G. Plastiline: another unsuspected danger in display causing black spots on bronzes. VDR Beiträge. 2006;2:112-6.

3. May J. James May's toy stories. London: Conway; 2009.

4. Moss A. Beginner's guide to sculpting characters in clay. Worcester: 3DTotal Publishing; 2017

5. Mossman S. Early plastics: perspectives, 1850-1950. London: Leicester University Press; 1997.

6. Miller FA, Wilkins $\mathrm{CH}$. Infrared spectra and characteristic frequencies of inorganic ions. Anal Chem. 1952;24:1253-94.

7. Derrick MR, Stulik D, Landry JM. Infrared spectroscopy in conservation science. Los Angeles: Getty Conservation Institute; 1999.

8. Andersson MP, Hem CP, Schultz LN, Nielsen JW, Pedersen CS, Sand KK, Okhrimenko DV, Johnsson A, Stipp SLS. Infrared spectroscopy and density functional theory investigation of calcite, chalk and coccoliths-do we observe the mineral surface? J Phys Chem A. 2014;118:10720-9.

9. Galván-Ruiz M, Hernández J, Baños L, Noriega-Montes J, Rodríguez-García ME. Characterisation of calcium carbonate, calcium oxide and calcium hydroxide as starting point to the improvement of lime for their use in construction. J Mater Civ Eng. 2009;21:694-8.

10. Baglioni M, Poggi G, Ciolli G, Fratini E, Giorgi R, Baglioni P. A Triton X-100-based microemulsion for the removal of hydrophobic materials from works of art: SAXS characterisation and application. Materials 2018;11:1144

11. Boccia Paterakis A. The influence of conservation treatments and environmental storage factors on corrosion of copper alloys in the Ancient Athenian Agora. J Am Inst Conserv. 2003;42:313-39.

12. Xuan S, Zhang Y, Zhou Y, Jiang W, Gong X. Magnetic Plasticine: a versatile magnetorheological material. J Mater Chem. 2012;22:13395-400.

13. Mandrile L, Giovannozzi AM, Pennecchi F, Saverino A, Lobascio C, Rossi AM. Direct detection and quantification of molecular surface contaminants by infrared and Raman spectroscopy. Anal Methods. 2015;7:2813-21.

14. Houmard M, Nunes EHM, Vasconcelos DCL, Berthomé G, Joud JC, Langlet M, Vasconcelos WL. Correlation between sol-gel reactivity and wettability of silica films deposited on stainless steel. Appl Surf Sci. 2014;289:218-23.

15. Lin CY, Tjeerdema RS. Crude oil, oil, gasoline and petrol. In: Jorgensen SE, Fath BD, editors. Encyclopedia of ecology. Amsterdam: Elsevier; 2008. p. 797-805.
16. Brown RA, Kay MI, Kelliher JM, Dietz WA. Analysis of oxidised paraffins by combined techniques. Anal Chem. 1967;39:1805-11.

17. Gracia N, Thomas S, Bazin P, Duponchel L, Thibault-Starzyk F, Lerasle O. Combination of mid-infrared spectroscopy and chemometric factorisation tools to study the oxidation of lubricating base oils. Catal Today. 2010;155:255-60

18. Nazir M. Analysis of paraffin wax oxidates by differential infrared spectrometry. Anal Chem. 1985;57:1110-2.

19. Salvadori B, Errico V, Mauro M, Melnik E, Dei L. Evaluation of gypsum and calcium oxalates in deteriorated mural paintings by quantitative FTIR spectroscopy. Spectrosc Lett. 2003;36:501-13.

20. Anbalagan G, Mukundakumari S, Sakthi Murugesan K, Gunasekaran S Infrared, optical absorption and EPR spectroscopic studies on natural gypsum. Vib Spectrosc. 2009;50:226-30.

21. Margenot AJ, Calderón FJ, Goyne KW, Mukome FND, Parikh SJ. IR spectroscopy, soil analysis applications. In: Lindon JC, Tranter GE, Koppenaal DW, editors. Encyclopedia of spectroscopy and spectrometry. Oxford: Academic Press; 2017. p. 448-54.

22. Salama W, El Aref M, Gaupp R. Spectroscopic characterisation of iron ores formed in different geological environments using FTIR, XPS, Mössbauer spectroscopy and thermoanalyses. Spectrochim Acta A. 2015;136:1816-26

23. Stuart BH. Infrared spectroscopy: fundamentals and applications. Chichester: Wiley; 2004.

24. Krendlinger $E$, Wolfmeier $U$, Schmidt $H$, Heinrichs FL, Michalczyk G, Payer W, Dietsche W, Boehlke K, Hohner G, Wildgruber J. In: Elvers B, editor. UIIman's encyclopedia of industrial chemistry. Weinheim: Wiley; 2015. https ://doi.org/10.1002/14356007.a28_103.pub2.

25. Thomas A, Matthaus B, Fiebig HJ. Fats and fatty oils. In: Elvers B, editor. UIIman's encyclopedia of industrial chemistry. Weinheim: Wiley-VCH; 2015 https://doi.org/10.1002/14356007.a10 173.pub2.

26. Madejova J. FTIR techniques in clay mineral studies. Vib Spectrosc. 2003:31:1-10.

27. Bratt Lauridsen C, Wøhlk Hansen L, Brock-Nannestad T, Bendix J, Pilkjær Simonsen K. A study of stearyl alcohol bloom on Dan Hill PVC dolls and the influence of temperature. Stud Conserv. 2017:62:445-55.

28. Klisińska-Kopacz A, Łydżba-Kopczyńska B, Czarnecka M, Koźlecki T, del Hoyo Mélendez J, Mendys A, Kłosowska-Klechowska A, Obarzanowski M, Frączek P. Raman spectroscopy as a powerful technique for the identification of polymers used in cast sculptures from museum collections. J Raman Spectrosc. 2018:50:213-21.

29. Tabb DL, Koenig JL. Fourier transform infrared study of plasticised and unplasticised poly(vinyl chloride. Macromolecules. 1975;8:929-34.

30. Berard MT, Daniels CA, Summers JW, Wilkes CE. PVC handbook. Munich: Hanser; 2005.

\section{Publisher's Note}

Springer Nature remains neutral with regard to jurisdictional claims in published maps and institutional affiliations.

\section{Submit your manuscript to a SpringerOpen ${ }^{\circ}$ journal and benefit from:}

- Convenient online submission

- Rigorous peer review

- Open access: articles freely available online

- High visibility within the field

Retaining the copyright to your article

Submit your next manuscript at springeropen.com 